SESSION II

MANIPULATION IN VITRO ET AMÉLIORATION ANIMALE

\title{
Molecular genetics and its possible implications to livestock improvement
}

\author{
K.H. SEIFART \\ Institut für Physiologische Chemie I, 3550 Marburg, Lahnberge, B.R.D.
}

\begin{abstract}
Significant achievements have recently been made in the area of molecular genetics which have greatly advanced our knowledge concerning the structure and function of the genome in eukaryotic cells. These developments not only influence our understanding of gene expression, important for phenomena of cell differentiation, the diversity of antibody production and malignant cell growth, but they may also have far reaching consequences for the industrial production of useful proteins and the possible cure of genetic defects. Moreover, it is conceivable, that retently developed techniques could be applied to animal genetics and livestock improvement, the scope and limitations of which will be discussed.
\end{abstract}

\section{Die Genkartierung bei landwirtschaftlichen Nutztieren : gegenwärtige Situation und Aussichten für die Zukunft}

\author{
G. STRANZINGER, R. FRIES and G. DOLF \\ Eidg. Techn. Hochschule Zürich, Institut für Tierproduktion, \\ Gruppe Tierzucht, ETH-Zentrum, CH-8092 Zürich, Schweiz
}

Die Genkartierung umfasst alle Untersuchungen über Kopplungs- und Syntäniegruppen und Chromosomenkarten. Verglichen mit dem Wissen über Humanchromosomen und den Labortiergenkarten, gibt es bei landwirtschaftlichen Nutztieren sehr wenige Ergebnisse. Die Berücksichtigung von Genkarten im Zuchtgeschehen erlaubt eine Vorhersage des Selektionsveriaufes.

Die Methoden der Genkartierung werden im Zusammenhang mit den gegenwärtigen Kenntnissen auf diesem Gebiet bei landwirtschaftlichen Nutztieren dargestellt. Ausser beim Huhn, wo eine gute Genkarte vorliegt, kennt man z.Z. bei den übrigen Nutztieren neben den geschlechtschromosomalen Kopplungsgruppen auch einige Syntänie- und Kopplungsgruppen auf autosomen Chromosomen.

Beim Schwein weisen neueste eigene Untersuchungen in Verbindung mit Literaturangalen darauf hin, dass das autosome Chromosom $\mathrm{Nr}$. 15 (Readind System) die G-und S-Blutgruppensystemloci und die bekannte Kopplungsgruppe PHI, Hal, H-Blutgruppe und 6-PGD trägt.

Weitere Ergebnisse werden mit Zellhybridisations- und Restriktionsenzymanalysen erwartet. Diese Untersuchungen sollen dazu beitragen, die Kenntnisse über den Genomaufbau zu vermehren und die damit verbundenen Verhältnisse zur Leistungsvererbung aufzuklären. 